\title{
ESTRATIFICAÇÃO IN VITRO DE EMBRIÕES ZIGÓTICOS DE PESSEGUEIRO EM DIFERENTES MEIOS DE CULTURA E CONCENTRAÇÕES DE SACAROSE ${ }^{1}$
}

\author{
LETÍCIA REIS ${ }^{2}$, IDEMIR CITADIN ${ }^{3}$, GENER AUGUSTO PENSO², \\ SILVIA SCARIOTTO ${ }^{4}$, AMÉRICO WAGNER JÚNIOR ${ }^{3}$
}

RESUMO- A embriocultura permite desenvolver embriões de sementes que não germinariam em condições convencionais de semeadura. Esta técnica é útil na obtenção de cultivares de pessegueiro com maturação precoce. O uso de genótipos diferentes faz com que sejam necessários ajustes ao protocolo. O objetivo deste trabalho foi testar quatro tipos de meio de cultura (WPM, SH, MS e SBH), em duas concentrações de sacarose (1,5 e $3 \%$ ), a fim de avaliar qual a melhor combinação para o cultivo de embriões de pessegueiro in vitro. Os genótipos utilizados como modelo do estudo foram 'Conserva 1129', em 2009, e 'Conserva 844', em 2010. Avaliaram-se a germinação, o desenvolvimento na fase in vitro, o comprimento de caule, número de folhas, sobrevivência das plântulas e formação de rosetas, em casa de vegetação. Considerando as condições em que os experimentos foram conduzidos, pode-se concluir que a estratificação e a germinação de embriões imaturos de pessegueiro in vitro melhoram quando realizadas em meios com maior concentração salina e de sacarose. Termos para indexação: Prunus persica, pêssegos de maturação precoce,embriocultura, resgate de embriões.

\section{IN VITRO STRATIFICATION OF PEACH ZIGOTIC EMBRYOS IN DIFFERENT CULTURE MEDIA AND SUCROSE CONCENTRATIONS}

\begin{abstract}
The embryo culture technique allows developing embryos of the seeds that could not germinate in conventional planting conditions. This technique is very useful to improve breeding programmes of earlymaturing peach cultivars. The use of different genotypes makes to be necessary adjustments to the protocol. The objective of this study was to test four culture medium (WPM, SH, MS and SBH) and two sucrose concentrations (1.5 and 3\%) to find the best combination for growing peach embryos in vitro. The genotypes used as a model were 'Conserva 1129', in 2009, and 'Conserva 844', in 2010. There were evaluated the germination (quality of germination and percentage of normal germination) and in vitro development (roots and steam length, and number of leaves and secondary roots); the stem length, leaf number, percentage of embryo survival and formation of rosettes, during greenhouse establishment. Considering the conditions under which the experiments were conducted, it can be concluded that in vitro stratification and germination of immature peach embryos were improved when performed in media with higher salt concentration of sucrose. Index terms: Prunus persica, early-maturing peach, embryo culture, embryo rescue.
\end{abstract}

\section{INTRODUÇÃO}

Dentre os métodos mais aplicados no melhoramento genético do pessegueiro, destaca-se a hibridação, seguida pelo plantio das sementes originadas deste processo (MONET; BASSI, 2008). Porém, sementes oriundas de frutas de maturação precoce possuem baixa porcentagem de germinação atribuída ao reduzido desenvolvimento do embrião. Cultivares que apresentam maturação inferior a 100 dias têm a maturação da fruta antecedida à do embrião, resul- tando na redução de germinação. Quando o ciclo da fruta (floração a colheita) estiver compreendido entre 75 e 90 dias, é necessário que se faça o complemento da maturação do embrião, utilizando-se, para isso, de meios de cultivo específicos, técnica conhecida como cultivo de embriões. Porém, quando esse período for inferior a 75 dias, a técnica é denominada cultivo de óvulos (RASEIRA; EINHARDT, 2010), exigindo condições de cultivo ainda mais complexas. A má germinação das sementes de pessegueiros precoces é consequência do processo de maturação do fruto,

${ }^{1}$ (Trabalho 056-12). Recebido em: 09-01-2012. Aceito para publicação em: 27-06-2012.

${ }^{2}$ Acadêmicos do curso de Agronomia da UTFPR, Câmpus Pato Branco. E-mails: lereis04@hotmail.com; generpenso@hotmail.com ${ }^{3}$ Prof. do Programa de Pós-Graduação em Agronomia da Universidade Tecnológica Federal do Paraná - UTFPR Campus Pato Branco. Via do conhecimento, km 01. 85503-390. E-mails: idemir@utfpr.edu.br (autor para correspondência), americowagner@utfpr.edu.br ${ }^{4}$ Eng. Agr., Mestre, UTFPR Campus Pato Branco. E-mail: silviascariotto@yahoo.com.br 
pois o rápido endurecimento do caroço restringe o acúmulo de matéria orgânica na amêndoa, tornando-o imaturo fisiologicamente. Genótipos com essa característica genética não acumulam reservas cotiledonares suficientes para suprir as necessidades dos embriões, provocando o abortamento destes, no período de amadurecimento do fruto. No entanto, se mantidas in vitro, em meio de cultura adequado, sob estratificação a frio-úmido, logo que extraídas dos frutos maduros, germinam satisfatoriamente (ARBELOA et al., 2009). Com isso, a técnica de cultivo de embriões, antes do abortamendo destes, torna-se essencial para salvar um número máximo de progênies híbridas em um programa de melhoramento (AKINBO et al., 2010).

O cultivo de embriões consiste na retirada de embriões zigóticos de óvulos e sementes, e posteriormente colocá-los sob condições assépticas de desenvolvimento, com uso de meio de cultura adequado e reguladores de crescimento para término de seu desenvolvimento. Este processo é dependente de muitos fatores, entre os quais , genótipo, explante, idade do embrião, composição básicas dos meios de cultivo, reguladores de crescimento, intensidade e qualidade de luz, fotoperíodo, temperatura e fatores endógenos. Angelo et al.(2011), utilizando o resgate de embrões, obtiveram 76 \% de plantas desenvolvidas de híbridos interespecificos entre Elaeis guineensis x E. Oleifera. Uma et al. (2011) obtiveram 88\% de sobrevivência em híbridos de bananeira. Pérez-Hernández e Grajal-Martín (2011), com hibridos de manga, obtiveram eficiência acima de $83 \%$ de germinação. A embriocultura também é utilizada no avanço de gerações, como, por exemplo, no tomateiro, em cujo emprego da técnica se conseguem 3 gerações por ano, em contraste com o método convencional que se obtêm 1 a 2 gerações por ano (GEBOLOĞLU et al. 2011). Quando empregada em videira, na obtenção de cultivares apirênicas, a técnica da embriocultura reduz de 6 a 8 anos o desenvolvimento de cultivares, além de garantir maior eficiência da reprodução (SINGH et al., 2011). Em mandioca, a técnica é utilizada para a redução do tempo de dormência em híbridos interespecíficos, além de aumentar a germinação, fatores considerados grandes gargalos no melhoramento desta cultura (AKINBO et al., 2010). Na cultura da azeleia (Rhododendron sinsii), a embriocultura tem sido utilizada no resgate de embriões poliploides (EECKHAUT et al., 2010).

Diante do exposto, o objetivo deste trabalho foi testar meios de cultura com diferentes concentrações de sacarose a fim de avaliar qual a melhor combinação para a estratificação e a germinação de embriões de pessegueiro in vitro.

\section{MATERIAL E MÉTODOS}

Os experimentos foram conduzidos no Laboratório de Cultura de Tecidos da Universidade Tecnológica Federal do Paraná - Câmpus Pato Branco (PR).

Foram utilizadas sementes provenientes de polinização aberta dos genótipos Conserva 1129 (ciclo 2009/2010) e Conserva 844 (ciclo 2010/2011). O período que compreendeu da floração à frutificação foi de 96 e 108 dias para Conserva 1129 e Conserva 844, respectivamente. Os frutos de cada genótipo foram colhidos no início da maturação, quando a cor de fundo dos mesmos passou de verde para amarelo (veraison), sendo imediatamente encaminhados ao Laboratório de Cultura de Tecidos, onde foram desinfestados por 10 minutos em solução de hipoclorito de sódio a 0,5\% e 5 minutos em solução de álcool a 70\%. As sementes foram extraídas dos frutos em câmara de fluxo laminar, sob condições assépticas, retirando-se das sementes o tegumento que as recobria. As sementes sem o tegumento foram inoculadas individualmente, em tubos de ensaio contendo meio de cultivo: SH (Meio de STWART e HSU - STEWART; HSU, 1977); MS (Meio de MURASHIGE e SKOOG - MURASHIGE; SKOOG, 1962); SBH (Meio de SMITH; BAILEY e HOUGH - SMITH et al., 1969) e WPM (Wood Plant Medium, LLOYD et al., 1980) e duas concentrações de sacarose nos mesmos, sendo de $1,5 \%$ e $3 \%$. O delineamento experimental foi o inteiramente casualizado, em fatorial 4 x 2 (meio de cultivo $\mathrm{x}$ teor de sacarose), com 4 repetições, cada qual constituída de 10 tubos de ensaio contendo um embrião (unidade experimental).

Posteriormente, os tubos de ensaio, devidamente vedados e identificados, permaneceram em temperatura constante de $5 \pm 1^{\circ} \mathrm{C}$ e no escuro, por 60 dias. Decorrido este período, os tubos com embrião foram deixados à temperatura ambiente por 2 dias, ainda no escuro e, em seguida, a $24 \pm 1^{\circ} \mathrm{C}$, por sete dias, expostos à luz (2.000 lux de intensidade) para clorofilação. Em seguida, as plântulas foram retiradas dos tubos e transferidas para a casa de vegetação, constituindo-se na aclimatização das mesmas. As plântulas recém-tiradas dos tubos foram plantadas em sacos plásticos contendo mistura de substrato latossolo: areia: vermiculita ${ }^{\circledR}$ na proporção de 1:1:1 (v/v).

Para avaliação da germinação dos embriões, após a saída da câmara fria, os tubos de ensaio contendo os embriões foram mantidos por dois dias à temperatura ambiente, no escuro, e então avaliados por meio da atribuição de notas de 1 a 5, quanto 
à germinação dos mesmos, sendo: 1) ausência de germinação; 2) germinação anormal apenas com cotilédones abertos; 3) germinação anormal apenas com emissão de radícula; 4) germinação anormal apenas com emissão de caulículo, e 5) germinação normal apresentando caulículo e radícula. Determinou-se, também, o percentual de germinação normal (percentual de embriões com nota 5).

Para a avaliação do desenvolvimento dos embriões, após sete dias de exposição em câmara de crescimento, as plântulas foram retiradas dos tubos de ensaio e mediram-se os comprimentos de caulículo e de raiz principal, as contagens de número de folíolos e de raízes secundárias. As plântulas com condições de sobrevivência (presença de caulículo e/ou radícula) foram transferidas para casa de vegetação, enquanto as demais foram descartadas.

As avaliações da porcentagem de plantas com enrosetamento das folhas foram realizadas 15 dias após o plantio e aos 75 dias deste período, ambos em casa de vegetação, sendo avaliados o comprimento de caule e o percentual de pegamento das mudas, levando-se em conta todas as plantas vivas, sem distinção quanto à presença de rosetas.

A normalidade dos erros experimentais foi verificada pelo teste de Shapiro-Wilk, e a homogeneidade de variância, pelo teste de Bartlett, com o uso do aplicativo computacional $\mathrm{R}$ ( $\mathrm{R}$ development core team, 2010). Os dados que não atenderam aos pressupostos matemáticos foram transformados pela $\sqrt{\mathrm{x}+1}$ ou $\operatorname{ar} \cos$ eno $=(\mathrm{x} / 100)^{1 / 2}$ ou e então submetidos à análise de variância; e as médias, comparadas pelo teste de Tukey $(p \leq 0,05)$.

\section{RESULTADOS E DISCUSSÕES}

Quanto ao desenvolvimento de embriões, avaliados por nota, não foi observado interação entre tipos de meio de cultura e concentração de sacarose tanto para a Conserva 1129 quanto para a Conserva 844. Porém, é possível observar diferença significativa entre meios para ambos os genótipos, e entre concentrações de sacarose apenas para a Conserva 844, observando-se o melhor desempenho na concentração de 3\%. O pior desenvolvimento de embriões foi observado no meio WPM, diferindo significativamente dos demais para a Conserva 844, porém diferindo apenas de SBH para a Conserva 1129 (Tabela 1).

Para percentual de germinação normal do genótipo Conserva 1129, houve interação significativa entre tipos de meio e concentração de sacarose. O meio WPM apresentou o pior desempenho, acompanhando o observado para as notas de desenvolvimen- to. No meio SBH e WPM não foram observados efeitos da concentração de sacarose sobre a germinação normal do embrião. Para o meio MS, a concentração de $3 \%$ de sacarose foi superior ao de $1,5 \%$, porém o inverso foi observado para o meio SH (Tabela 2).

A baixa resposta no desenvolvimento do embrião observada neste experimento, quando se utilizou o meio WPM, indica necessidade prévia de cultivo em outros meios, com concentrações de sacarose variando de $1,5 \%$ a $3 \%$, conforme o tipo de meio utilizado (Tabela 2). Durante a germinação, embriões usualmente requerem baixos níveis de sais inorgânicos associados a aminoácidos e vitaminas (STEWART; HSU, 1977). Além disso, deve-se ter cuidado com os níveis hormonais no meio, para apoiar o crescimento e o desenvolvimento normais dos embriões. Liu et al. (2007), testando diferentes meios e concentrações de hormônios, obtiveram melhores resultados com 1/2MS combinado com $4 \mathrm{mg}$ $\mathrm{L}^{-1}$ 6-BA e $0,5 \mathrm{mg} \mathrm{L}^{-1}$ de AIB, tanto para germinação como para crescimento de pessegueiro. Estes autores sugerem que o abortamento do embrião acontece devido a um inadequado equilíbrio hormonal. Por outro lado, o excesso de hormônios muitas vezes pode induzir à formação de calos (FULLER et al., 2011).

No desenvolvimento de caulículo e no número de folíolos do genótipo Conserva 1129, não houve efeito significativo da interação entre os dois fatores estudados, bem como efeito simples do teor de sacarose. Quanto ao tipo de meio de cultura, WPM foi o único a diferir significativamente dos demais para ambas as variáveis, apresentado a menor e a maior média para o desenvolvimento de caulículo e número de folíolos respectivamente (Tabela 3). Com isso, verifica-se que o maior número de folíolos, nem sempre pode ser considerado indicativo de melhor desempenho da plântula, pois, muitas vezes, isso é decorrência da concentração desses folíolos em forma de roseta, fator indesejável na obtenção de seedlings.

Para o número de raízes secundárias e o comprimento de radícula principal de 'Conserva 1129’, houve interação para ambas as variáveis. Verificou-se que as menores médias foram obtidas com meio WPM, independentemente do teor de sacarose utilizado. Quando se utilizou 1,5\% de sacarose, obteve-se maior número de raízes com os meios SBH, SH e MS, sendo que, para este último, também houve superioridade significativa com $3,0 \%$ de sacarose (Tabela 4).

A mesma superioridade do meio MS com 3\% de sacarose também foi verificada para o comprimento da raiz principal, diferindo dos demais meios. Já o meio SBH apresentou maior comprimento da raiz 
principal com 1,5\% de sacarose, não diferindo do MS (Tabela 4).

Para o genótipo Conserva 844, não houve interação entre concentração de sacarose e meio de cultura para comprimento de caulículo e radícula, e para número de folíolos e de raízes secundárias (Tabela 5), sendo o mesmo efeito de não significância obtido para os teores de sacarose, com estas variáveis. Já para tipo de meios de cultura, não houve diferença significativa apenas para comprimento de radícula principal. No meio de cultura WPM, não foi possível avaliar as características de desenvolvimento das plântulas de pessegueiro 'Conserva 844', uma vez que este meio não proporcionou germinação eficiente dos embriões, o que, consequentemente, impossibilitou o surgimento de plântulas viáveis para avaliação (Tabela 5). Hamill et al. (2009) testaram WPM solidificado com ágar, vermiculita com WPM líquido, vermiculita com WPM acrescido de ágar e estratificação convencional. Esses autores observaram que o substrato vermiculita com WPM acrescido de ágar melhorou a sobrevivência e o desenvolvimento de embriões germinados.

Para comprimento de caulículo, o meio $\mathrm{SH}$ apresentou a maior média, porém não diferindo significativamente do meio $\mathrm{SBH}$. Quanto ao número de folíolos e de raízes secundárias, os três meios comparados (SBH, MS e SH) não diferiram significativamente entre si.

Nos resultados referentes ao percentual de rosetas, observa-se que não houve interação significativa entre o teor de sacarose e o tipo de meio de cultura para ambos os genótipos. Porém, no genótipo Conserva 1129, o uso de 1,5\% de sacarose proporcionou menor percentual de rosetas em comparação a 3,0\%. Já para o genótipo Conserva 844, não foi observado diferença significativa entre os teores de sacarose para essa variável (Tabela 6). O meio MS foi o que apresentou menor percentual de rosetas, em ambos os genótipos, porém este meio não diferiu significativamente dos meios WPM e SH para 'Conserva 1129' e do SBH para 'Conserva 844', o que demonstra que a resposta morfogenética em um meio de cultura difere de acordo com o genótipo utilizado.

A formação de rosetas é fator dependente da cultivar, conforme visualizado na Tabela 6 . Porém, condições externas de temperatura também influenciam na formação de rosetas. Já na fase de aclimatação das plantas, outro fator que influencia para a formação de rosetas é a temperatura da casa de vegetação, no qual, em condições de temperaturas entre 15 e $20^{\circ} \mathrm{C}$, reduzem a formação das mesmas, enquanto próximas de $30^{\circ} \mathrm{C}$ aumentam-nas (TOPP et al., 2008). Portanto, o percentual de rosetas para ambas as cultivares, embora apresente tendência de redução com o uso do meio MS, foi influenciado também pelos fatores externos descritos anteriormente e não mensurados neste trabalho.

Quanto ao crescimento de caule, observou-se que os genótipos Conserva 1129 e Conserva 844 não apresentaram interação entre teor de sacarose e tipos de meio de cultura. Para concentração de sacarose, não houve diferença significativa. Por outro lado, o meio de cultura apresentou significância, tendo o meio MS possibilitado os maiores crescimentos de caule de ambos os genótipos avaliados, porém, para 'Conserva 1129’, este meio não diferiu do meio SH (Tabela 6).

Em relação ao percentual sobrevivência do genótipo Conserva 1129, em casa de vegetação, houve interação significativa entre tipo de meio e concentração de sacarose. A estratificação de sementes na menor concentração de sacarose $(1,5 \%)$ proporcionou o maior percentual de sobrevivência de seedlings em casa de vegetação apenas quando o meio utilizado foi o SH. Contudo, para o meio WPM, a maior sobrevivência foi obtida com uso de 3\% de sacarose e, para os demais meios (MS, SBH), as médias não diferiram significativamente entre si para os teores de sacarose testados. Para ambas as concentrações de sacarose (1,5 e 3,0\%), houve $100 \%$ de sobrevivência dos seedlings com uso do meio MS, porém este não diferiu significativamente do meio SBH nos teores de $1,5 \%$ e 3,0\% de sacarose, e também do SH para menor concentração do açúcar (Tabela 7). Vale ressaltar que WPM apresentou o menor desempenho in vitro, acarretando o plantio de menor número de plântulas em comparação aos demais. Já para o genótipo Conserva 844, não houve significância na interação entre concentração de sacarose e tipo de meio e, no fator teor de sacarose, para o percentual de sobrevivência (Tabela 8). Também não foi observado diferença significativa entre os meios SBH, MS e SH. Ressalta-se que o meio WPM não proporcionou plântulas viáveis para transferência e aclimatização na casa de vegetação.

O uso de recipientes fechados, meios nutritivos e fontes de carbono criam condições ideais para o desenvolvimento de embriões. $\mathrm{O}$ fornecimento contínuo de hidratos de carbono, a partir do meio, para incentivar o crescimento e a sobrevivencia in vitro, uso de luz abaixo da intensidade ideal, presença limitada de $\mathrm{O}_{2}$ e alta umidade relativa, reduz a atividade fotossintética das plântulas (BADR et al., 2011). Para estimular a fotoautotrofia, o ideal seria reduzir ou eliminar o carboidrato do meio, na última fase de cultivo in vitro, o que poderia estimular o enraizamento in vitro, outro fator importante 
envolvido na aclimatização e capaz de determinar a plasticidade adaptativa das plantas (SANTANA et al., 2008; CHAARI RKHIS et al., 2011). Nesse sentido, em futuros experimentos, pretende-se testar a redução na concentração de sacarose apenas na fase final da estratificação, principalmente para seedlings anormais, que não apresentam radícula, além de se testar diferentes concentrações de reguladores de crescimento no meio de cultura.

TABELA 1 - Nota de germinação dos embriões dos pessegueiros 'Conserva 1129’ (ciclo 2009/2010) e 'Conserva 844' (ciclo 2010/2011), em relação ao teor de sacarose e tipo de meio de cultura. UTFPR Câmpus Pato Branco, 2011.

\begin{tabular}{ccc}
\hline & Germinação dos embriões \\
\hline \multirow{2}{*}{ Concentrações de sacarose } & $\begin{array}{c}\text { Cons. 1129 } \\
\text { (ciclo 2009/2010) }\end{array}$ & $\begin{array}{c}\text { Cons. 844 } \\
\text { (ciclo 2010/2011) }\end{array}$ \\
\cline { 2 - 3 } & Nota $^{\text {NS }}$ & Nota \\
\hline 1,5\% & 4,41 & $2,02 \mathrm{~b}$ \\
$3 \%$ & 4,35 & $2,54 \mathrm{a}$ \\
\hline Tipos de meio & Nota & Nota \\
\hline WPM & $3,90 \mathrm{~b}$ & $1,06 \mathrm{~b}$ \\
SBH & $4,62 \mathrm{a}$ & $2,91 \mathrm{a}$ \\
MS & $4,50 \mathrm{ab}$ & $2,54 \mathrm{a}$ \\
SH & $4,51 \mathrm{ab}$ & $2,61 \mathrm{a}$ \\
\hline CV(\%) & 9,55 & 20,04
\end{tabular}

Médias seguidas pela mesma letra não diferem significativamente, pelo teste de Tukey $(P \leq 0,05)$. ${ }^{\text {NS }}$ não significativo pelo teste $\mathrm{F}$. 1$)$ Ausência de germinação; 2) Germinação anormal apenas com cotilédones abertos; 3) Germinação anormal apenas com emissão de radícula; 4) Germinação anormal apenas com emissão de caulículo, e 5) Germinação normal apresentando caulículo e radícula

TABELA 2 - Percentagem de germinação normal de embriões zigóticos de pessegueiro 'Conserva 1129' de acordo com a concentração de sacarose e meio de cultura utilizado. UTFPR Câmpus Pato Branco, 2011.

\begin{tabular}{ccccc}
\hline \multirow{2}{*}{ Concentrações de sacarose } & \multicolumn{4}{c}{ Germinação normal (\%) } \\
\cline { 2 - 5 } & \multicolumn{4}{c}{ Tipos de meio } \\
\cline { 2 - 5 } & WPM & SBH & MS & SH \\
\hline $1,5 \%$ & $12,5 \mathrm{aB}$ & $77,5 \mathrm{aA}$ & $52,5 \mathrm{bA}$ & $82,5 \mathrm{aA}$ \\
$3 \%$ & $20,0 \mathrm{aB}$ & $77,5 \mathrm{aA}$ & $82,5 \mathrm{aA}$ & $55,0 \mathrm{bA}$ \\
\hline $\mathrm{CV}(\%)$ & \multicolumn{4}{c}{30,84} \\
\hline
\end{tabular}

Médias seguidas por letras iguais minúsculas na coluna e maiúsculas iguais, na linha, não diferem pelo teste de Tukey $(P \leq 0,05)$.

TABELA 3 - Desenvolvimento de caulículo e número de folíolos de plântulas de pessegueiro 'Conserva 1129’ com relação ao tipo de meio de cultura e concentração de sacarose. UTFPR Câmpus Pato Branco, 2011.

\begin{tabular}{ccc}
\hline Concentrações de sacarose & ${\text { Caulículo }(\mathrm{cm})^{\mathrm{NS}}}^{\mathrm{N}}$ & Folíolos (número) $^{\mathrm{NS}}$ \\
\hline $1,50 \%$ & 4,07 & 4,53 \\
$3 \%$ & 3,65 & 3,57 \\
\hline Tipos de meio & Caulículo $(\mathrm{cm})$ & Folíolos (número) \\
\hline WPM & $2,80 \mathrm{~b}$ & $5,95 \mathrm{a}$ \\
SBH & $4,16 \mathrm{a}$ & $3,75 \mathrm{~b}$ \\
MS & $3,91 \mathrm{a}$ & $3,68 \mathrm{~b}$ \\
SH & $4,58 \mathrm{a}$ & $2,83 \mathrm{~b}$ \\
\hline CV $(\%)$ & 12,26 & 24,57
\end{tabular}

Médias seguidas pela mesma letra não diferem significativamente, pelo teste de Tukey $(P \leq 0,05)$. ${ }^{\text {NS }}$ não significativo pelo teste $\mathrm{F}$. 
TABELA 4 - Número de raízes secundárias e comprimento de radícula principal de plântulas de pessegueiro 'Conserva 1129' de acordo com a concentração de sacarose e meio de cultura. UTFPR Câmpus Pato Branco, 2011.

\begin{tabular}{|c|c|c|c|c|}
\hline \multirow{3}{*}{$\begin{array}{l}\text { Concentrações de } \\
\text { sacarose }\end{array}$} & \multicolumn{4}{|c|}{ Raiz secundária (número) } \\
\hline & \multicolumn{4}{|c|}{ Tipos de meio } \\
\hline & WPM & $\mathrm{SBH}$ & MS & $\mathrm{SH}$ \\
\hline $1,50 \%$ & $0,18 \mathrm{aB}$ & $5,72 \mathrm{aA}$ & $5,37 \mathrm{bA}$ & $5,74 \mathrm{aA}$ \\
\hline $3 \%$ & $0,00 \mathrm{aC}$ & $3,49 \mathrm{bB}$ & $7,96 \mathrm{aA}$ & $3,19 \mathrm{bB}$ \\
\hline $\mathrm{CV}(\%)$ & \multicolumn{4}{|c|}{37,59} \\
\hline \multirow{3}{*}{$\begin{array}{l}\text { Concentrações de } \\
\text { sacarose }\end{array}$} & \multicolumn{4}{|c|}{ Radícula principal (cm) } \\
\hline & \multicolumn{4}{|c|}{ Tipos de meio } \\
\hline & WPM & $\mathrm{SBH}$ & MS & $\mathrm{SH}$ \\
\hline $1,50 \%$ & $0,05 \mathrm{aC}$ & $4,33 \mathrm{aA}$ & $3,46 \mathrm{aAB}$ & $2,75 \mathrm{aB}$ \\
\hline $3 \%$ & $0,04 \mathrm{aD}$ & $2,55 \mathrm{bB}$ & $4,01 \mathrm{aA}$ & $1,28 \mathrm{bC}$ \\
\hline $\mathrm{CV}(\%)$ & \multicolumn{4}{|c|}{27,12} \\
\hline
\end{tabular}

Médias seguidas por letras iguais minúsculas na coluna e maiúsculas iguais, na linha, não diferem pelo teste de Tukey $(P \leq 0,05)$.

TABELA 5 - Desenvolvimento de caulículo e de radícula de acordo com seu comprimento, números de raízes secundárias e de folíolos de plântulas do pessegueiro ‘Conserva 844’ (ciclo 2010/2011) com relação ao tipo de meio de cultura e concentração de sacarose. UTFPR Câmpus Pato Branco, 2011.

\begin{tabular}{ccccc}
\hline $\begin{array}{c}\text { Concentrações } \\
\text { de sacarose }\end{array}$ & Caulículo $(\mathrm{cm})^{\mathrm{NS}}$ & ${\text { Radícula princ. }(\mathrm{cm})^{\mathrm{NS}}}$ & Folíolos (número) $^{\mathrm{NS}}$ & Raiz sec. (número) $^{\mathrm{NS}}$ \\
\hline $1,50 \%$ & 33,07 & 0,79 & 0,51 & 0.91 \\
$3 \%$ & 34,32 & 0,96 & 0,68 & 0.84 \\
\hline Tipos de meio & Caulículo (cm) & Radícula princ. $(\mathrm{cm})^{\mathrm{NS}}$ & Folíolos (número) $^{\mathrm{NS}}$ & Raiz sec. (número) $^{\mathrm{NS}}$ \\
\hline WPM & $0,00 \mathrm{c}$ & - & - & - \\
SBH & $51,07 \mathrm{ab}$ & 1,21 & 0,63 & $0,66 \mathrm{a}$ \\
MS & $32,36 \mathrm{~b}$ & 1,47 & 0,81 & $1,12 \mathrm{a}$ \\
SH & $53,07 \mathrm{a}$ & 1,03 & 0,93 & $1,70 \mathrm{a}$ \\
\hline CV $(\%)$ & 12,73 & 91,20 & 15,96 & 32,51 \\
\hline
\end{tabular}

Médias seguidas pela mesma letra não diferem significativamente, pelo teste de Tukey $(P \leq 0,05)$. ${ }^{\text {Ns }}$ não significativo pelo teste $\mathrm{F}$. Os dados para a variável comprimento de caulículo foram transformados por $\sqrt{\mathrm{x}+1}$.

TABELA 6 - Percentual de rosetas observadas nos primeiros 15 dias de aclimatização e Comprimento de caule após 75 dias em casa de vegetação, em relação à concentração de sacarose e tipo de meio de cultura, para plântulas de pessegueiro ‘Conserva 1129' (ciclo 2009/2010) e 'Conserva 844' (ciclo 2010/2011). UTFPR Câmpus Pato Branco, 2011.

\begin{tabular}{|c|c|c|c|c|}
\hline \multirow{2}{*}{$\begin{array}{c}\text { Concentrações } \\
\text { de sacarose }\end{array}$} & \multicolumn{2}{|c|}{ Cons. 1129} & \multicolumn{2}{|c|}{ Cons. 844} \\
\hline & Rosetas (\%) & Caule $(\mathrm{cm})^{\mathrm{NS}}$ & Rosetas (\%) ${ }^{\mathrm{NS}}$ & Caule $(\mathrm{cm})^{\mathrm{NS}}$ \\
\hline $1,50 \%$ & $17,87 \mathrm{~b}$ & 11,75 & 33,07 & 9,47 \\
\hline $3 \%$ & $43,08 \mathrm{a}$ & 10,06 & 34,32 & 12,48 \\
\hline Tipos de meio & Rosetas (\%) & Caule $(\mathrm{cm})$ & Rosetas (\%) & Caule $(\mathrm{cm})$ \\
\hline WPM & $24,99 \mathrm{ab}$ & $8,75 \mathrm{~b}$ & - & - \\
\hline $\mathrm{SBH}$ & 47,36 a & $10,36 \mathrm{~b}$ & $49,36 \mathrm{ab}$ & $12,48 \mathrm{~b}$ \\
\hline MS & $11,42 \mathrm{~b}$ & $18,82 \mathrm{a}$ & $32,36 \mathrm{~b}$ & 20,36 a \\
\hline $\mathrm{SH}$ & $38,12 \mathrm{ab}$ & $12,83 \mathrm{ab}$ & $53,06 \mathrm{a}$ & $11,06 \mathrm{~b}$ \\
\hline $\mathrm{CV}(\%)$ & 9,55 & 32,98 & 20,04 & 45,51 \\
\hline
\end{tabular}

Médias seguidas pela mesma letra não diferem pelo teste Tukey $(\mathrm{P} \leq 0,05)$. NS Não significativo pelo teste $\mathrm{F}$. Os dados para da variável comprimento de caule do genótipo Cons. 844, foram transformados por Raiz de $\mathrm{x}+1$. 
TABELA 7 - Percentual de sobrevivência das plântulas do genótipo ‘Conserva 1129’ em casa de vegetação de acordo com o tipo de meio e concentração de sacarose. UTFPR Câmpus Pato Branco, 2011.

\begin{tabular}{ccccc}
\hline \multirow{2}{*}{ Concentrações de sacarose } & \multicolumn{4}{c}{ Sobrevivência (\%) } \\
\cline { 2 - 5 } & WPM & SBH & MS & SH \\
\cline { 2 - 5 } & $57,37 \mathrm{bB}$ & $89,44 \mathrm{aA}$ & $100 \mathrm{aA}$ & $85,76 \mathrm{aA}$ \\
\hline $1,5 \%$ & $76,25 \mathrm{aBC}$ & $88,815 \mathrm{aAB}$ & $100 \mathrm{aA}$ & $67,63 \mathrm{bC}$ \\
\hline CV & \multicolumn{4}{c}{13,04} \\
\hline \multicolumn{5}{c}{} \\
\cline { 2 - 5 }
\end{tabular}

Médias seguidas por letras iguais minúsculas na coluna e maiúsculas iguais, na linha, não diferem pelo teste de Tukey $(P \leq 0,05)$.

TABELA 8 - Percentual de sobrevivência das plântulas do genótipo ‘Conserva 844' em casa de Vegetação, de acordo com o tipo de meio e concentração de sacarose. UTFPR Câmpus Pato Branco, 2011.

\begin{tabular}{cc}
\hline Concentrações de sacarose & Sobrevivência (\%) ${ }^{\mathrm{NS}}$ \\
\hline $1,5 \%$ & 44,37 \\
$3 \%$ & 51,87 \\
\hline Meio & Sobrevivência (\%) \\
\hline WPM & - \\
SBH & 76,25 \\
MS & 53,75 \\
SH & 62,50 \\
\hline CV(\%) & 13,81
\end{tabular}

${ }^{N S}$ não significativo pelo teste $\mathrm{F}$.

\section{CONCLUSÃO}

Considerando as condições em que os experimentos foram conduzidos, pode-se concluir que a estratificação e a germinação de embriões imaturos de pessegueiro in vitro melhoram quando realizadas em meios com maior concentração salina e de sacarose.

\section{AGRADECIMENTO}

A Embrapa Clima temperado, pela disponibilização dos genótipos; ao CNPq, pela bolsa concedida; à Fundação Araucária, pelo apoio financeiro concedido (Convênio nº :402/2009).

\section{REFERÊNCIAS}

AKINBO, O.; LABUSCHAGNE, M.; FREGENE, M. Embryo rescue as a method to develop and multiply a backcross population of cassava (Manihot esculenta Crantz) from an interspecific cross of Manihot esculenta ssp. Flabellifolia. African Journal of Biotechnology, Nairoba, v. 9 n.42, p. 7.058-7.062, 2010.
ANGELO, P.C da S.; MORAES, L.A.C.;LOPES, R.;SOUSA, N.R.; CUNHA, R.N.V da.; QUISEN, R.C. In vitro rescue of interspecific embryos from Elaeis guineensis x E. oleifera (Arecaceae). Revista de Biologia Tropical, San Jose, v. 59, n.3, p. 10811088, 2011.

ARBELOA, A.; DAORDEN, M.; GARCÍA, E.; ANDREU, P.; MARI'N, J.A. In Vitro Culture of 'Myrobalan' (Prunus cerasifera Ehrh.) Embryos. Hortscience, Alexandria, v. 44, n.6, p.1.672-1.674, 2009.

BADR, A.;ANGERS, P.; DESJARDINS, Y. Metabolic profiling of photoautotrophic and photomixotrophic potato plantlets (Solanum tuberosum) provides new insights into acclimatization. Plant Cell, Tissue and Organ Culture, Dordrecht, v.107, p.13-24, 2011.

CHAARI RKHIS, A.; MAALEJ, M.; DRIRA, N.; STANDARDI, A. Micropropagation of olive tree olea Europaea L. 'Oueslati’ Turkish Journal of Agriculture and Forestry. Turkish Journal of Agriculture and Forestry, Ankara, v. 35, n.4, p.403-412, 2011. 
EECKHAUT, T.; DE KEYSER, E.; VAN HUYLENBROECK, J. In vitro assisted breeding of evergreen azalea as a tool for assortment extension. Acta Horticulturae, The Hague, v,.29, p.55-60, 2010.

FULLER, R.J.; LIDDIARD, V.M.; HESS, J.R.; CARMAN, J.G. Improving cotton embryo culture by simulating in ovulonutrient and hormone levels. In Vitro Cellular and Developmental Biology Plant, Columbia, v. 47, v.410-419, 2011.

GEBOLOĞLU; N.; BOZMAZ, S.; AYDIN, M.; ÇAKMAK, P. The role of growth regulators, embryo age and genotypes on immature embryo germination and rapid generation advancement in tomato (Lycopersicon esculentum Mill.). African Journal of Biotechnology, Nairobe, v.10, n.24, p. 4.8954.900, 2011.

HAMILL, S.; PROMCHOT, S.; BIGNELL, G.; GILES, J.; TOPP, B. Vermiculite improves early development and survival of low chill stone-fruit embryos rescued in vitro. Acta Horticulturae, The Hague, v.829, n.16 p. 79-83, 2009.

LIU, W.; CHEN, X.; LIU, G.; LIANG, Q.; HE, T.; FENG, J. Interspecific hybridization of Prunus persica with P. armeniaca and P. salicina using embryo rescue. Plant Cell Tissue Organ and Culture, Dordrecht, v.88, p.289-299, 2007.

LLOYD, G.; McCOWN, B. Comercially feasible micropropagation of Mountain laurel, Kalmia latifolia, by use of shoot tipe culture. Proceedings of the International Plant Propagators Society, Raleigh, v.30, p.421-427, 1980.

MONET, R.; BASSI, D. Classical genetics and breeding. In: LAYNE, D. R.; BASSI, D. The peach: botany, production and uses. Wallingford: CAB International, 2008. p.61-84.

MURASHIGE, T.; SKOOG, F. A revised medium for rapid growth and bioassays with Tabacco tissue cultures. Physilogia Plantarum, Copenhagem, v.15, p.473-496, 1962.
PÉREZ-HERNÁNDEZ, J.B.; GRAJAL-MARTÍN, M.J. In vitro culture of immature zygotic mango embryos and plantlet development. HortScience, Alexnadria, v.46, n.11, p. 1.528-1.532, 2011.

R DEVELOPMENT CORE TEAM. R: a language and environment for statistical computing. Vienna: R Foundation for Statistical Computing. Vienna, 2010. 288p.

RASEIRA, M.C.B.; EINHARDT, P.M. Resgate de embriões em pessegueiro: tempo de incubação. Scientia Agraria, Curitiba, v.11, n.6, p.445-450, 2010.

SANTANA, J.R.F.; PAIVA, R.; RESENDE, R.K.S.; CASTRO, E.M.; PEREIRA, F D.; OLIVEIRA, L.M. Estímulo do comportamento fotoautotrófico durante o enraizamento in vitro de Annona glabra L., ii. aspectos da anatomia da folha antes da aclimatização. Ciência Agrotécnica, Lavras, v.32, n.2, p.640-644, 2008.

SINGH, N.V.; SINGH, S.K.;SINGH, A.K. Standardization of embryo rescue technique and bio-hardening of grape hybrids (Vitis vinifera L.) using Arbuscular mycorrhizal fungi (AMF) under sub-tropical conditionsVitis. Journal of Grapevine Research, Berlin, v.50, n.3, p.115-118, 2011.

SMITH, C.A.; BAYLEY, C.H.; HOUGH, L.F. Methods for germinating seeds of some species with especial reference to growing seedlings form immature embryos. New Jersey: Agricultural Experiment Station, 1969. 29p. (Bulletin, 823).

STEWART, J.M.; HSU, C.L. In ovulo embryo and seedling development of cotton (Gossypium hirsutum L.). Planta, New York, v.137, p.113-117, 1977.

TOPP, B.L.; SHERMAN, W.B.; RASEIRA, M.C.B. Low-chill cultivar development. In.: LAYNE, D. R.; BASSI, D. The peach: botany, production and uses. Wallingford: CAB International, 2008. p.106-138.

UMA; S.; LAKSHMI, S.; SARASWATHI, M. S.; AKBAR, A.; MUSTAFFA, M.M. Embryo rescue and plant regeneration in banana (Musa spp.). Plant Cell and Tissue Organ Culture, Dordrecht, v.105, p.105-111, 2011. 